\title{
Management of Cataracts in Pediatric Patients with Developmental Delay at a Tertiary Care Pediatric Hospital
}

\author{
Sugi Panneerselvam1', Madhuri Chilakapati1,2, Alexis Moisiuc ${ }^{2}$, Kimberly G. Yen ${ }^{1,2}$ \\ ${ }^{1}$ Department of Ophthalmology, Baylor College of Medicine, Houston, TX, USA \\ ${ }^{2}$ Department of Ophthalmology and Pediatrics, Texas Children's Hospital, Houston, TX, USA \\ Email:kgyen@texaschildrens.org
}

How to cite this paper: Panneerselvam, S., Chilakapati, M., Moisiuc, A. and Yen, K.G. (2021) Management of Cataracts in Pediatric Patients with Developmental Delay at a Tertiary Care Pediatric Hospital. Open Journal of Ophthalmology, 11, 152-162. https://doi.org/10.4236/ojoph.2021.112012

Received: April 23, 2021

Accepted: May 25, 2021

Published: May 28, 2021

Copyright $\odot 2021$ by author(s) and Scientific Research Publishing Inc. This work is licensed under the Creative Commons Attribution International License (CC BY 4.0).

http://creativecommons.org/licenses/by/4.0/

\begin{abstract}
Background: Childhood cataract causing visual impairment can compound developmental delay (DD) if left untreated. Current literature in children with DD is limited; thus, we evaluated cataract etiology, challenges, and treatment compliance in this group. Purpose: To report the presentation and challenges associated with cataract management in children with developmental delay (DD) at a tertiary care pediatric hospital. Methods: Retrospective review of 100 patients (173 eyes) presenting with cataracts and DD from February 2014 to December 2017. Results: 100 patients (173 eyes) were included. 27 patients had unilateral cataracts and 73 bilateral. The average age was 120.55 months (SD 63.77, range 5.87 - 243.16); the average follow-up period was 57.7 months (SD 139.14, range 1.03 - 1412.30). $61 \%$ of patients (55\% eyes) underwent medical management for cataracts due to: cataract was not visually significant ( $66 \%$ eyes), parent deferred surgery ( $11 \%$ eyes), self-abusive behavior (14\% eyes), and medical conditions that limited visual recovery (9\% eyes). 32\% of patients were unable to perform objective visual acuity by age 5 . Patients with self-abusive behavior were more likely to present with or develop retinal detachment $(\mathrm{RD})(35 \%)$ compared to those without self-abusive behavior $(6 \%)(p=0.0028)$. A statistically significant difference in the difficulty of examination $(\mathrm{p}<0.0001)$ and poor compliance of glasses wear $(\mathrm{p}<$ 0.0001 ) was found in nonverbal patients. Surgical complications occurred in $39 \%$ of eyes. Those with intraocular lens placement after cataract extraction were more likely to develop visual axis opacification (27\% eyes) than those who remained aphakic ( $9 \%$ eyes) $(\mathrm{p}=0.0313)$. Conclusion: Cataract extraction in pediatric patients with DD can be associated with success, however, providers should prepare for limitations in managing these patients.
\end{abstract}




\section{Keywords}

Cataract Surgery, Developmental Delay, Pediatric Cataract, Intraocular Lens

\section{Introduction}

There are approximately 1.4 million blind children worldwide, with an additional 500,000 children becoming blind annually. Of these cases, childhood cataracts contribute to $14 \%$ of these cases and are most associated with congenital rubella infection and inherited developmental disorders [1]. In general, children with developmental delay (DD) have a higher frequency of ocular conditions, including cataracts, and should be screened appropriately [2] [3] [4]. If left untreated, cataracts can negatively affect psychosocial, educational, and visual development in patients who carry the diagnosis of DD [5]. Unlike cataract management in adult patients, cataract management in children incurs additional challenges, such as a need for general anesthesia, limitations in examination and treatment due to cooperation, presence of amblyopia, and changes in refractive error over time [6] [7].

Pediatric patients with DD and cataracts present providers with unique challenges. Contributing factors that challenge cataract management in children with DD include the need to interpret nonverbal cues, the presence of comorbid medical conditions limiting visual diagnosis and recovery, and the potential for self-injurious behavior. Current literature correlating etiology, type of cataract, complications, and compliance with treatment in children with DD are limited.

In the United States, 1 of every 6 children aged 3 - 17 has DD, and this number has been increasing over the last decade [8]. The purpose of this study is to report the etiology and characteristics of cataracts in patients with $\mathrm{DD}$, explore contributing factors that challenge cataract management in children with $\mathrm{DD}$, and provide direction for providers managing cataracts in these children, based on a population study at a tertiary-care center.

\section{Methods}

This study was approved by the Institutional Review Board of Baylor College of Medicine and Texas Children's Hospital and adhered to the tenets of the Declaration of Helsinki. A retrospective review was conducted of the electronic medical record for patients with "pediatric cataract" seen between February 27, 2014 and December 29, 2017, in a tertiary care pediatric ophthalmology hospital. A total of 702 pediatric patients with cataract diagnoses were identified. Patients were included if they had an International Classification of Diseases (ICD) diagnosis of developmental delay, were between the ages of 0 to 19 years, and had at least one month of follow-up.

602 patients were excluded for lack of one-month minimum follow-up, not carrying a DD diagnosis, or being inaccurately coded as having cataracts. Medi- 
cal records were reviewed for demographics, comorbid diagnoses, pre-operative, intra-operative, and post-operative information, visual acuity, and treatment.

Patient demographic information included age at initial presentation, gender, gestational age at birth, race, ethnicity, verbal or nonverbal nature, and presence or absence of self-injurious behavior. Self-injurious behavior was defined as head hitting, head banging, or aggressive eye poking or prodding reported by the child's parents. Cataracts were classified by type, characteristics, laterality, and etiology. Cataracts were categorized as congenital if the age of diagnosis was within one year of birth and developmental if the age of diagnosis was greater than one year [6]. Cataract diagnosis was based on examinations performed by pediatric ophthalmologists at Texas Children's Hospital or written reports from ophthalmologists at external institutions.

Comorbid diagnoses recorded included the presence of amblyopia, strabismus, retinopathy of prematurity (ROP), retinal detachment (RD), other posterior segment conditions, and systemic medical conditions. Pre-operative information collected included type and date of surgery, if performed, including the presence of primary posterior capsulotomy or anterior vitrectomy, intraocular lens (IOL) placement and method, and reasons for medical management if cataract surgery was not performed. The surgical technique followed guidelines published in the Infant Aphakia Treatment Study (IATS) [1] [2]. Post-operatively, all patients received topical steroids and antibiotics; patients who did not receive an IOL also received cycloplegics. All patients were advised to wear safety glasses or a shield post-operatively for 1 month. Post-operative complications, such as aphakic glaucoma, $\mathrm{RD}$, visual axis opacification (VAO), strabismus, and need for a second surgery were also noted. Visually significant VAO was noted when retinoscopy was unable to be performed due to the VAO or if a decline in vision could be attributed to the VAO. Aphakic glaucoma was diagnosed utilizing IATS criteria of intraocular pressure (IOP) greater than $21 \mathrm{~mm} \mathrm{Hg}$ with anatomic variations suggesting glaucomatous changes [9].

Best corrected visual acuity was recorded from the first and most recent visit. Those with no light perception or who could not perform objective visual acuity measurement by age 5 were noted. In those patients who were able to cooperate for visual acuity examination, the Snellen or HOTV method was used.

Compliance with drops, glasses, contacts, or patching was recorded. Noncompliance with eye drops was noted in any patient who did not receive all doses of drops in the recommended course. Glasses compliance was recorded via parental history. If the patient wore glasses less than $50 \%$ of the recommended time per day for two separate visits, noncompliance with glasses wear was recorded. Failure to patch was also assessed via the patient's legal guardians, and was deemed unsuccessful in those who did not patch greater than $50 \%$ of the recommended time for two separate clinic visits.

Summary statistics included means and standard deviations for continuous variables. Analysis for data including two categorical variables was completed 
using Fisher's exact test. Analyses were conducted using SPSS with a statistical significance of $p=0.05$ as the standard for this exploratory study.

\section{Results}

100 patients, or 173 eyes, with cataracts were included in the study (Table 1). 27 patients had unilateral cataracts and 73 patients had bilateral cataracts. $52 \%$ of patients were white, and $60 \%$ were male. The average age of patients included in the study was $117.04 \pm 66.34$ months at presentation, and the average length of follow-up was $57.7 \pm 139.14$ months (interquartile range [IQR]: 21.79 to 62.15 ). $55 \%$ of eyes (95/173) included in the study received medical management of cataracts, with the reasons for deferral of surgery detailed in Table 2 . Of the $45 \%$ of eyes $(78 / 173)$ that underwent surgery, $42 \%$ of eyes (33/78) had IOL placement

Table 1. Patient characteristics $(\mathrm{N}=100)$.

\begin{tabular}{ll}
\hline Demographics & \\
\hline Sex & 60 patients (60\%) \\
Male & 40 patients (40\%) \\
Female & \\
Race/ethnicity & 52 patients (52\%) \\
White & 24 patients (24\%) \\
African American/Black & 20 patients (20\%) \\
Hispanic & 4 patients (4\%) \\
Asian & \\
Cataract Laterality & 27 patients (27\%) \\
Unilateral & 73 patients (73\%) \\
Bilateral & $117.04 \pm 66.34$ months \\
Average Age & $57.7 \pm 139.14$ months \\
Average Length of Follow Up & $154.32 \pm 363.72$ months \\
Average Age at Time of Surgery & $42.15 \pm 58.49$ months \\
Average Length of Follow up of Surgery Group & \\
\hline
\end{tabular}

Table 2. Reasons for medical management of cataract patients. ${ }^{\star}$ Denotes the number of patients including those who had at least one eye that was medically managed, even if the other eye was operated on.

\begin{tabular}{ccccc}
\hline & $\begin{array}{c}\text { Number of Eyes } \\
\text { Undergoing Medical } \\
\text { Management }\end{array}$ & $\begin{array}{c}\text { \% Eyes Undergoing } \\
\text { Medical } \\
\text { Management }\end{array}$ & $\begin{array}{c}\text { Number of Patients } \\
\text { Undergoing Medical } \\
\text { Management* }\end{array}$ & $\begin{array}{c}\text { \% Patients Undergoing } \\
\text { Medical Management* }\end{array}$ \\
\hline Visually insignificant cataract & 63 & $66 \%$ & 41 & $67 \%$ \\
Parent deferred surgery & 10 & $11 \%$ & 5 & $8 \%$ \\
Self-abusive behavior & 13 & $14 \%$ & 9 & $15 \%$ \\
Medical conditions limiting visual recovery & 9 & $9 \%$ & 61 & $10 \%$ \\
Total & 95 & $55 \%$ & $61 \%$ & $61 \%$ \\
\hline
\end{tabular}


and $58 \%$ of eyes $(45 / 78)$ eyes were left aphakic. $32 \%$ of patients $(32 / 100)$ with DD were born premature (range 22-37 weeks estimated gestational age). Of those, 50\% (32/64 eyes) were diagnosed with bilateral retinopathy of prematurity (ROP).

\subsection{Etiology and Morphology}

Morphology and etiology of cataract are shown in Figure 1 and Figure 2, respectively. $36 \%(62 / 173)$ of the cataracts were congenital. Morphology of cataract is further characterized in Figure 3 by etiology of cataract. Iatrogenic causes, such as previous retinal surgery, radiation, steroid use, or a combination of these factors, were more likely to result in posterior subcapsular cataracts (PSC) $(\mathrm{P}<0.0001) .83 \%(15 / 18)$ of iatrogenic eyes developed PSC cataracts compared to $17 \%(3 / 18)$ of other types of cataracts. $12 \%(19 / 155)$ of non-iatrogenic eyes developed PSC compared to $88 \%(136 / 155)$ with other types of cataracts $(\mathrm{P}<$ 0.0001). PSC were overall the most common cataract identified in patients with DD across all etiologies (20\% eyes, 34/173 eyes), followed by cortical (19\% eyes, $32 / 173$ eyes), white ( $12 \%$ eyes, $20 / 173$ eyes), and nuclear ( $12 \%$ eyes, $20 / 173$ eyes) cataracts. Cataracts linked to self-injurious etiologies were most commonly white cataracts ( $60 \%$ of eyes, $3 / 5$ eyes).

\subsection{Examination, Complications, and Treatment}

Difficulty with the examination, complications after surgery, and treatment adherence issues are summarized for providers in Table 3. Objective visual acuity

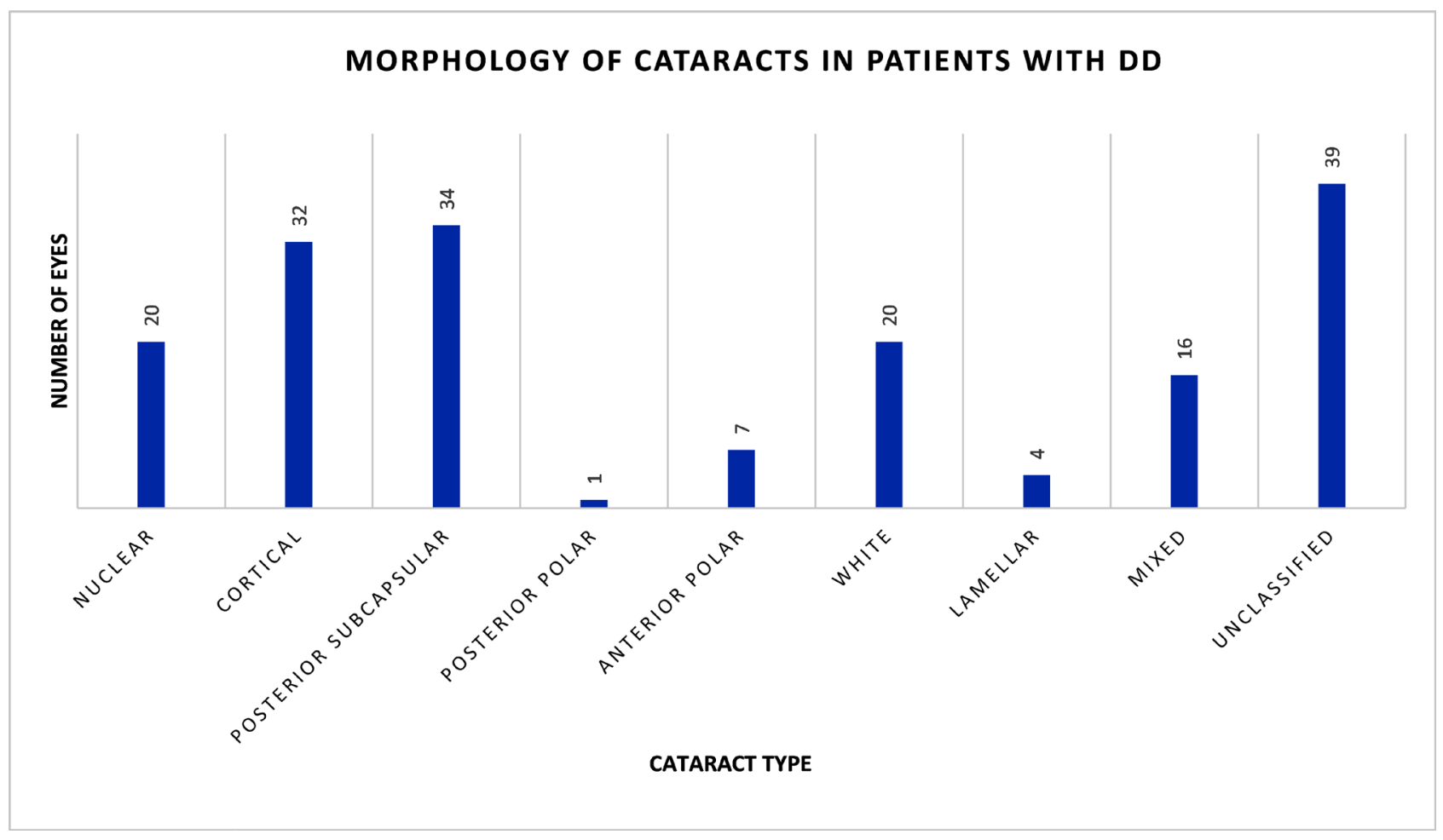

Figure 1. Morphology of cataracts in patients with developmental delays. 


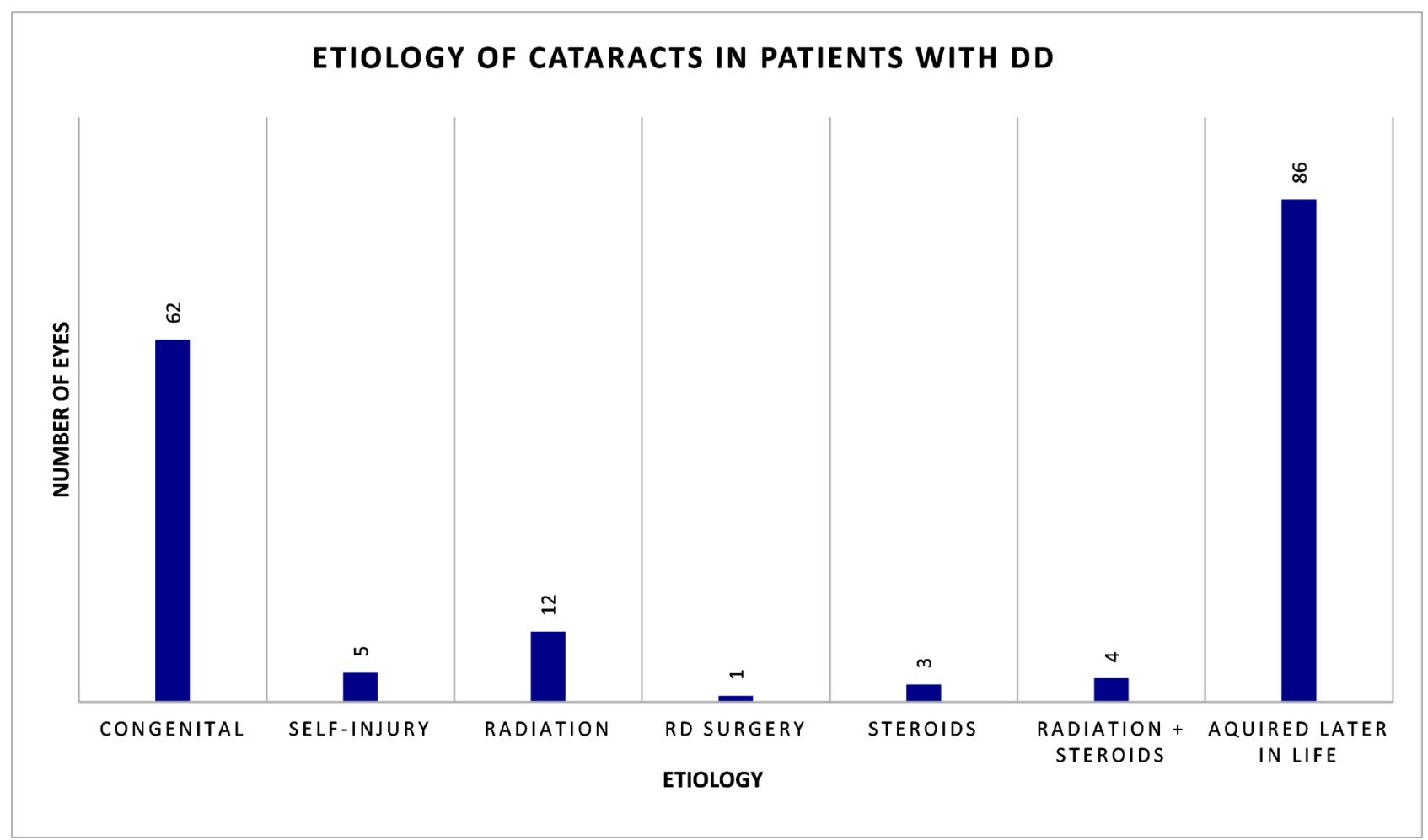

Figure 2. Etiology of cataracts in patients with developmental delays. (RD) Retinal Detachment.

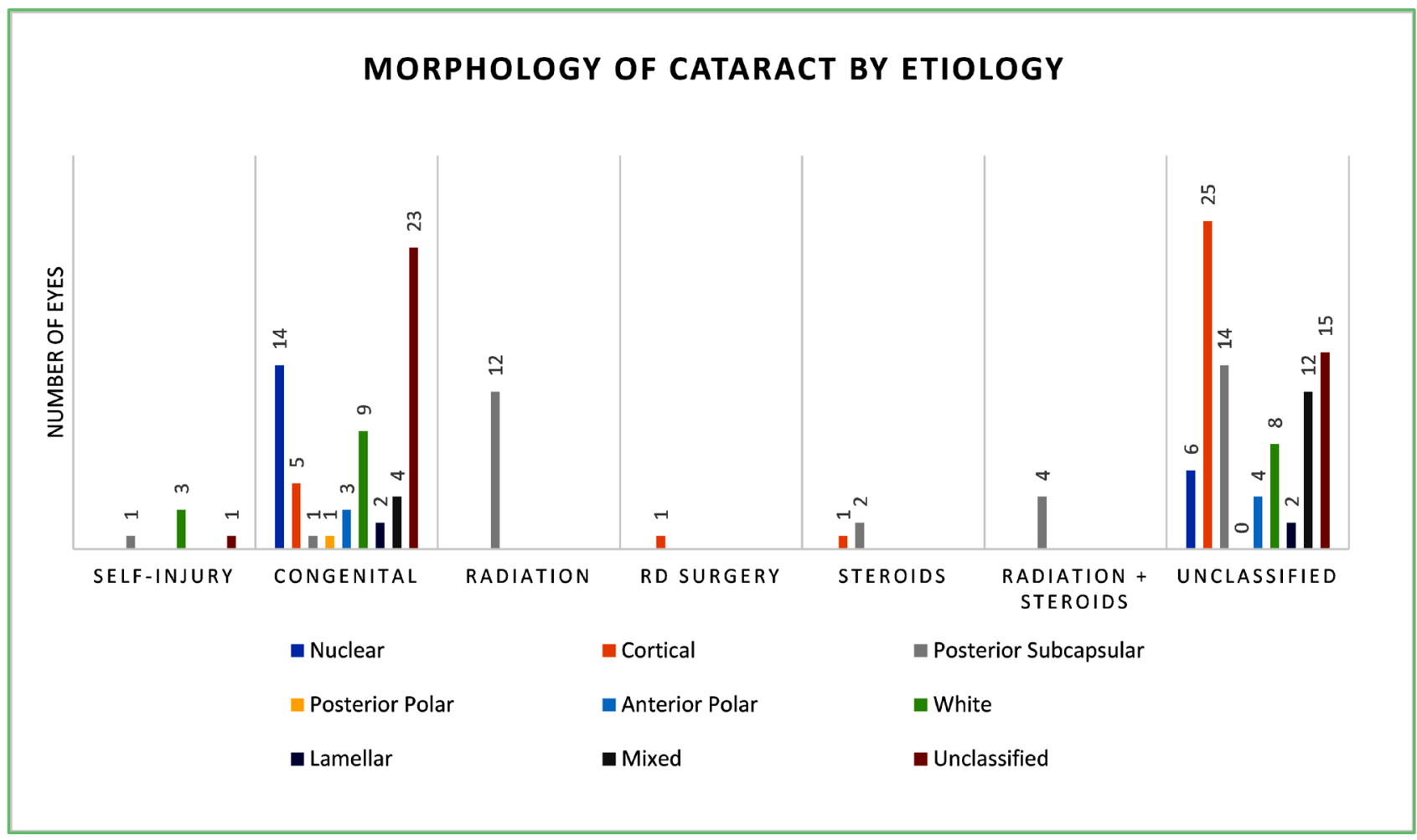

Figure 3. Morphology of cataract by etiology. (RD) Retinal Detachment. 
Table 3. Educational suggestions for providers treating cataracts in patients with developmental delays.

\begin{tabular}{|c|c|}
\hline Result & Recommendation \\
\hline $\begin{array}{l}\text { Objective visual acuity was not achievable due to } \\
\text { poor cooperation in } 32 \% \text { of patients over the age } \\
\text { of } 5 \text {. Poorer cooperation is more likely in } \\
\text { nonverbal patients than verbal patients. }\end{array}$ & $\begin{array}{l}\text { Providers should be aware of this challenge. The } \\
\text { red reflex exam and retinoscopy to determine the } \\
\text { visual significance of cataracts is a useful tool in } \\
\text { these instances. }\end{array}$ \\
\hline $\begin{array}{l}39 \% \text { of eyes in patients with DD developed a } \\
\text { complication, with aphakic glaucoma and visual } \\
\text { axis opacification being the most common } \\
\text { occurrences. }\end{array}$ & $\begin{array}{l}\text { Counsel families regarding the risk of these } \\
\text { postoperative occurrences and need for } \\
\text { intervention. Exam under anesthesia may be } \\
\text { required in some circumstances. }\end{array}$ \\
\hline $\begin{array}{l}\text { Visual axis opacification is more likely in patients } \\
\text { with IOLs than those who are aphakic. }\end{array}$ & $\begin{array}{l}\text { Visual axis opacification is a known occurrence } \\
\text { after pediatric cataract surgery. Counsel families } \\
\text { regarding the risk of these postoperative } \\
\text { occurrences. }\end{array}$ \\
\hline $\begin{array}{l}\text { Patching is universally difficult in both verbal } \\
\text { and nonverbal children with DD. }\end{array}$ & $\begin{array}{l}\text { Counsel families to anticipate this challenge and } \\
\text { be given options on alternative patch modalities. }\end{array}$ \\
\hline $\begin{array}{l}\text { Verbal patients are more compliant with glasses } \\
\text { treatment than nonverbal patients. }\end{array}$ & $\begin{array}{l}\text { Counsel families of nonverbal patients to } \\
\text { anticipate this challenge. In some situations, an } \\
\text { alternative method of refractive correction may } \\
\text { be considered. }\end{array}$ \\
\hline $\begin{array}{l}\text { Comorbid diagnoses of } \mathrm{RD} \text { and cataract are } \\
\text { more likely when the patient has self-injurious } \\
\text { behaviors. }\end{array}$ & $\begin{array}{l}\text { Maintain a higher suspicion for RD in patients } \\
\text { with DD and self-injurious behavior presenting } \\
\text { with complete cataracts. }\end{array}$ \\
\hline
\end{tabular}

was not achievable due to poor cooperation in $32 \%$ of patients over the age of 5 (25/78 patients), despite the average age of these poorly compliant patients being 145 months (12 years). Poor cooperation for the exam was noted to occur more frequently in nonverbal patients with $83 \%(43 / 52)$ of nonverbal patients classified as uncooperative compared to $23 \%(11 / 48)$ of verbal patients found to be uncooperative $(\mathrm{P}<0.0001)$.

The incidence of $\mathrm{RD}$ in patients with $\mathrm{DD}$ at the time of cataract evaluation was found to be higher in those who displayed self-injurious behavior compared to those without self-injurious behaviors $(\mathrm{P}=0.0028)$. Only $6 \%(5 / 83)$ of patients without self-abusive behavior presented with comorbid $\mathrm{RD}$ at the time of cataract evaluation, while $35 \%(6 / 17)$ of patients with self-abusive tendencies presented with both $\mathrm{RD}$ and cataracts. Of the patients with self-abusive behavior, 10/34 eyes had no light perception at the time of presentation, and 2/34 eyes could only blink to light.

Complications after surgery occurred in $39 \%$ of eyes that were managed surgically (30/78). 18\% (14/78 eyes) of eyes developed aphakic glaucoma, 17\% (13/78 eyes) developed VAO, $1 \%$ (1/78 eyes) developed RD after surgery due to self-injurious behavior, and 3\% (2/78 eyes) required removal of the IOL due to anterior chamber inflammation secondary to noncompliance with post-operative drops. Those with IOL placement after cataract extraction were more likely to develop VAO; $27 \%$ (9/33) of eyes with IOL developed VAO compared to $9 \%$ $(4 / 45)$ of aphakic eyes $(\mathrm{P}=0.0313)$. 
Amblyopia was diagnosed in $31 \%$ of patients (31/100 patients), and $71 \%$ of these (22/31 patients) were recommended to undergo patching treatment. 59\% $(13 / 22)$ of patients were not compliant with patching. No statistical difference was found in compliance with patching between verbal patients ( $8 \%$ eyes) compared to nonverbal patients (10\% eyes). Other recommended treatments included glasses or contacts in 56\% (96/173) of eyes. Compliance with glasses treatment in verbal patients with DD (97\% with good compliance) was better than nonverbal patients with DD ( $37 \%$ with good compliance) $(\mathrm{P}<0.0001)$.

\section{Discussion}

There has been a significant increase in the prevalence of DD over the last decade, and as a result, a necessity to improve targeted interventions [8]. A multispecialty approach is necessary to care for and determine resources needed for children with $\mathrm{DD}$, with ophthalmology being particularly important due to the high prevalence of ophthalmic conditions in this group [10]. To our knowledge, this is the first study to delineate the etiology and morphology of cataracts in patients with DD as well as explore the challenges in managing these patients.

It has been demonstrated that children with DD have ophthalmologic abnormalities at a higher prevalence than the general population [10]. Many children with DD have been found to have significant ophthalmic pathology even when there is no suspicion of eye-related problems [2]. Formal recommendations for ophthalmic screening in children with DD are not well-established, but many providers recommend performing an eye examination between 1 to 5 years [2] [4] [11]. As expected, patients with $\mathrm{DD}$ undergoing surgery for $\mathrm{RD}$, receiving radiation to the head, or using steroids are at increased risk for PSCs and should be monitored accordingly. This is consistent with existing data in non-DD populations, suggesting that PSC development in patients with these risk factors is independent of DD status [12] [13].

Cataract management and extraction in nonverbal pediatric patients with DD is generally successful, however, providers should prepare for limitations when managing these patients. The red reflex exam and cycloplegic retinoscopy, if tolerated, are most helpful in evaluating the visual significance of cataracts in nonverbal patients, as many cannot participate in a slit lamp examination in the clinic. In situations where clinic exams cannot be completed, exams under anesthesia may need to be utilized [14]. Furthermore, there is a higher incidence of difficulty wearing glasses, patching, and cooperating during clinical examination in nonverbal patients compared to verbal patients with DD. Providers should be aware that targeted counseling and additional efforts may be required to ensure adherence to examination and treatment.

Ocular self-injury, while uncommon, is an important consideration when evaluating patients with DD, as trauma is a common cause of cataracts [15]. Reports of self-inflicted blunt head trauma as a mechanism for cataract development also correlate with a higher incidence of vitreous hemorrhage, $\mathrm{RD}$, and 
self-enucleation at presentation in patients with DD [15] [16] [17]. Even without visible injury to the globe or eyelid, dense cataracts have been reported in patients with chronic headbanging behavior [17]. In our patient population, children with self-injurious behavior were more likely to present with $\mathrm{RD}$ and with a white cataract. This calls for provider awareness and targeted screening for self-injurious behavior and its associated morbidities when eliciting patient histories.

Surgical outcomes are generally favorable in patients with DD, but as expected, VAO is a frequent and expected complication particularly when IOLs are placed. VAO is more common in the pediatric population, occurring in up to $40 \%$ of patients undergoing cataract surgery [18]. Providers should educate patients and their families that YAG laser or surgical management may be necessary due to the development of VAO when an IOL is placed. On the other hand, our data suggest that aphakic glaucoma may be a more prevalent surgical complication in children with $\mathrm{DD}$ (18\% of eyes) compared to recent rates published in the general pediatric population $(6 \%-13 \%)$ [19] [20]. Studies from the early 1990 s report rates of aphakic glaucoma as high as $41 \%$ in pediatric patients, but advances in surgical techniques may play a role in the lower rates today [21]. Higher rates of complications in children with DD are consistent with existing literature, which states surgical complications in children with Trisomy 21 occur in $20 \%-60 \%$ of patients compared to $0 \%-28 \%$ of the general pediatric population. However, existing studies were limited by small sample size [3]. This difference in surgical outcomes between children with DD and the general pediatric population could be secondary to more medically complex cases, susceptible anatomy, or difficult post-surgical course. Higher rates of cataract surgery complications in children with DD correlate with the increased morbidity for this group from surgical interventions outside of ophthalmology as well [3].

Our study is limited by the fact that it is a single-center study and used a retrospective design; however, our diverse cohort in age, race, and ethnicity make our results more representative of pediatric patients with DD and cataracts. Future research on patterns of cataract etiology and management in specific forms of DD could be useful.

While the severity of DD cannot always be measured quantitatively, factors such as language ability and self-injurious behavior may be useful predictors of ease of visual examination, cataract surgery outcomes, and treatment compliance. Difficulty assessing objective visual acuity, poor patching compliance, self-abusive behavior, and poor compliance in glasses wear are potential challenges that may limit the ability to manage patients with DD. Educating providers regarding these challenges can help establish interventions for patients with DD and prepare both patients and providers for the difficulties in management.

\section{Acknowledgements}

We would like to thank the patients and their families for participation in this study. 


\section{Conflicts of Interest}

The authors declare no conflicts of interest regarding the publication of this paper.

\section{References}

[1] World Health Organization (1999) Preventing Blindness in Children. World Health Organization \& International Agency for the Prevention of Blindness, Report of a WHO/IAPB Scientific Meeting, 1-40.

[2] Ikeda, J., Davitt, B.V., Ultmann, M., Maxim, R. and Cruz, O.A. (2013) Brief Report: Incidence of Ophthalmologic Disorders in Children with Autism. Journal of Autism and Developmental Disorders, 43, 1447-1451. https://doi.org/10.1007/s10803-012-1475-2

[3] Santoro, S.L., Atoum, D., Hufnagel, R.B. and Motley, W.W. (2017) Surgical, Medical, and Developmental Outcomes in Patients with Down Syndrome and Cataracts. SAGE Open Medicine, 5. https://doi.org/10.1177/2050312117715583

[4] Haargaard, B. and Fledelius, H.C. (2006) Down's Syndrome and Early Cataract. British Journal of Ophthalmology, 90, 1024-1027. https://doi.org/10.1136/bjo.2006.090639

[5] Packwood, E.A., Cruz, O.A., Rychwalski, P.J. and Keech, R.V. (1999) The Psychosocial Effects of Amblyopia Study. Journal of AAPOS, 3, 15-17. https://doi.org/10.1016/S1091-8531(99)70089-3

[6] Zhang, H., Xie, L., Wu, X. and Tian, J. (2012) Long-Term Results of Pediatric Cataract Surgery after Delayed Diagnosis. Journal of AAPOS, 16, 65-69. https://doi.org/10.1016/j.jaapos.2011.09.012

[7] Trivedi, R.H. and Wilson, M.E. (2011) Prediction Error after Pediatric Cataract Surgery with Intraocular Lens Implantation: Contact versus Immersion A-Scan Biometry. Journal of Cataract and Refractive Surgery, 37, 501-505. https://doi.org/10.1016/j.jcrs.2010.09.023

[8] Zablotsky, B., Black, L.I., Maenner, M.J., Schieve, L.A., Danielson, M.L., Bitsko, R.H., Boyle, C.A., et al. (2019) Prevalence and Trends of Developmental Disabilities among Children in the United States: 2009-2017. Pediatrics, 144, e20190811. https://doi.org/10.1542/peds.2019-0811

[9] Beck, A.D., Freedman, S.F., Lynn, M.J., Bothun, E., Neely, D.E. and Lambert, S.R. (2012) Glaucoma-Related Adverse Events in the Infant Aphakia Treatment Study: 1-Year Results. Archives of Ophthalmology, 130, 300-305. https://doi.org/10.1001/archophthalmol.2011.347

[10] Black, K., McCarus, C., Collins, M.L.Z. and Jensen, A. (2013) Ocular Manifestations of Autism in Ophthalmology. Strabismus, 21, 98-102. https://doi.org/10.3109/09273972.2013.786733

[11] Malt, E., Dahl, R.C., Haugsand, T.M., Ulvestad, I.H., Emilsen, N.M., Hansen, B., Davidsen, E.M., et al. (2013) Health and Disease in Adults with Down Syndrome. Tidsskrift for den Norske Laegeforening, 133, 290-294. https://doi.org/10.4045/tidsskr.12.0390

[12] Nakashima, E., Neriishi, K. and Minamoto, A. (2006) A Reanalysis of Atomic-Bomb Cataract Data, 2000-2002: A Threshold Analysis. Health Physics, 90, 154-160. https://doi.org/10.1097/01.HP.0000175442.03596.63

[13] Chodick, G., Bekiroglu, N., Hauptmann, M., Alexander, B.H., Freedman, D.M., Doody, M.M., Sigurdson, A.J., et al. (2008) Risk of Cataract after Exposure to Low 
Doses of Ionizing Radiation: A 20-Year Prospective Cohort Study among US Radiologic Technologists. American Journal of Epidemiology, 168, 620-631. https://doi.org/10.1093/aje/kwn171

[14] Mahmoud, A.O., Ayanniyi, A.A. and Oyedepo, O.O. (2010) Pediatric Ophthalmic Indications for Examination under Anesthesia in Ilorin, Nigeria. Annals of African Medicine, 9, 181-183. https://doi.org/10.4103/1596-3519.68357

[15] Lee, Y.H., Lenhart, P.D. and Lambert, S.R. (2016) Cataract Secondary to Self-Inflicted Blunt Trauma in Children with Autism Spectrum Disorder. Journal of AAPOS, 20, 361-362. https://doi.org/10.1016/j.jaapos.2016.02.013

[16] Field, H.L. and Waldfogel, S. (1995) Severe Ocular Self-Injury. General Hospital Psychiatry, 17, 224-227. https://doi.org/10.1016/0163-8343(95)00031-L

[17] Spalter, H.F., Bemporad, J.R. and Sours, J.A. (1970) Cataracts Following Chronic Headbanging: Report of Two Cases. Archives of Ophthalmology, 83, 182-186. https://doi.org/10.1001/archopht.1970.00990030184010

[18] Shrestha, U.D. and Shrestha, M.K. (2014) Visual Axis Opacification in Children Following Paediatric Cataract Surgery. JNMA; Journal of the Nepal Medical Association, 52, 1024-1030. https://doi.org/10.31729/jnma.2807

[19] Repka, M.X. (2019) Cataract Surgery in Children from Birth to Less than 13 Years of Age in the PEDIG Registry: Status Three Years Following Surgery. Journal of American Association for Pediatric Ophthalmology and Strabismus, 23, e3. https://doi.org/10.1016/j.jaapos.2019.08.003

[20] Repka, M.X., Dean, T.W., Kraker, R.T., Bothun, E.D., Morrison, D.G., Lambert, S.R., Wallace, D.K., et al. (2019) Visual Acuity and Ophthalmic Outcomes in the Year after Cataract Surgery among Children Younger than 13 Years. JAMA Ophthalmology, 137, 817-824. https://doi.org/10.1001/jamaophthalmol.2019.1220

[21] Asrani, S., Freedman, S., Hasselblad, V., Buckley, E.G., Egbert, J., Dahan, E., Maselli, E., et al. (2000) Does Primary Intraocular Lens Implantation Prevent "Aphakic" Glaucoma in Children? Journal of AAPOS, 4, 33-39.

https://doi.org/10.1016/S1091-8531(00)90009-0 